\title{
Biblioteconomia, documentação e ciência da informação: história, sociedade, tecnologia e pós- modernidade
}

Jéssica Câmara Siqueira

\begin{abstract}
Mestranda do Programa de Pós Graduação em Ciência da Informação da ECA/USP.Especialização em Arquivos no IEB/USP.
\end{abstract}

Apresenta um panorama das formações socioculturais e as revoluções tecnológicas observadas ao longo da história, que influenciaram as origens e o desenvolvimento da Biblioteconomia, Documentação e Ciência da Informação. O panorama histórico apresentado, dialoga com as principais formações sociais e revoluções tecnológicas, permitindo a compreensão mais aprofundada de fenômenos, práticas e necessidades que refletem os escopos dos domínios da Biblioteconomia, Documentação e Ciência da Informação.Tal abordagem, ratifica as inter-relações entre os domínios apresentados, mas também salienta suas particularidades, o que corrobora a análise e as discussões acerca da Biblioteconomia, Documentação, Ciência da Informação na pós-modernidade.

Palavras-chave: Biblioteconomia; Documentação; Ciência da Informação; Tecnologia; História; Sociedade; Pós-modernidade.

\section{Librarianship, documentation and information science: history, society, technology and post-modernity}

Presents an overview of sociocultural formations and technological revolutions seen throughout history that influenced the origins and development of Library, Documentation and Information Science. The historical overview presented dialogues with the major technological revolutions and social formations, allowing for deeper understanding of phenomena, practices and 
requirements, which reflect the scope of the areas of Library, Documentation and Information Science. This approach ratified the inter-relationships between areas presented, but also stresses its peculiarities, which supports the analysis and discussions of Librarianship, Documentation, Information Science in post-modernity.

Keywords: Librarianship, Documentation;
Information;
modernity.

Recebido em 17.07.2010 Aceito em 18.10.2010

\section{Introdução}

$\mathrm{Na}$ tentativa de compreender melhor as relações histórico-sociais entre a Biblioteconomia, a Documentação e a Ciência da Informação, comumente abordadas sob o viés da organização da informação ou mera transcrição cronológica factual, será apresentada uma perspectiva que considera tanto as formações socioculturais como as diferentes revoluções tecnológicas para o delineamento dos escopos desses domínios. A fundamentação teórica utilizada para análise baseia-se, principalmente, em duas obras: O processo civilizatório de Darcy Ribeiro (2000) e as Tecnologias da Inteligência de Pierre Lévy (1998). A primeira traz um panorama histórico das principais formações e processos sociais, relacionando-os com as revoluções tecnológicas. A outra, discute como as ditas "tecnologias da inteligência" afetam os domínios Biblioteconomia, Documentação e Ciência da Informação, atualmente.

Para Ribeiro (2000), a história da humanidade pode ser compreendida a partir do entendimento de uma sucessão de revoluções tecnológicas e processos civilizatórios em que o homem passa de uma condição generalizada para uma vivência diferenciada. Para realizar uma evolução sociocultural, as sociedades humanas devem passar por dois processos simultâneos e mutuamente complementares: a autotransformação, responsável pela diversificação; e a homogeneização, responsável pela manutenção do patrimônio cultural. Além disso, há três imperativos que as influenciam: o caráter tecnológico, o social e o ideológico, elementos que permitem as formações socioculturais.

Segundo o autor, a evolução sociocultural é vista como "um movimento histórico de mudança dos modos de ser e de viver dos grupos humanos, desencadeado pelo impacto de sucessivas revoluções tecnológicas sobre as sociedades" (RIBEIRO, 2000, p. 15). Ou seja, os modelos conceituais da vida social se combinam com uma determinada tecnologia produtiva, que por sua vez procura ordenar as relações humanas, em um esforço de interpretar experiências e refletir sua perspectiva ideológica. Assim, todo sistema social se apoia sobre um sistema tecnológico e é determinado por este último, porém, todo sistema 
tecnológico funciona dentro de um sistema social e é consequentemente condicionado por ele.

A partir de tais pressupostos teóricos, Ribeiro correlaciona as revoluções tecnológicas com as formações socioculturais, com intuito de compreender os dois principais processos para evolução sociocultural: atualização histórica (homogeneização) e a aceleração evolutiva (diferenciação). Para isso classifica em oito as principais revoluções tecnológicas (Agrícola, Urbana, de Regadio, Metalúrgica, Pastoril, Mercantil, Industrial e Termonuclear); em quatro os processos civilizatórios (povos tribais, etnias nacionais, civilizações regionais e civilizações mundiais); e treze formações socioculturais (aldeias agrícolas indiferenciadas, hordas pastoris, estados rurais artesanais, impérios teocráticos de regadio, impérios mercantis escravistas, impérios despóticos salvacionistas, impérios mercantis salvacionistas, capitalismo mercantil, colonialismo, imperialismo industrial, neocolonialismo, socialismo e nacionalismo).

Já a obra de Lévy sobre as tecnologias intelectuais, nos reporta ao momento de atual de transição de paradigmas, que por um lado tem a perspectiva racional, positivista e disciplinar e de outro a fragmentada, pluridiversa e subjetiva face pós-moderna. Nesse contexto nos apresenta sua teoria sobre as ecologias cognitivas, gérmen de um coletivo pensante dinâmico, que ao utilizar as tecnologias intelectuais é capaz de delinear as práticas culturais e sociopolíticas da humanidade.

Enquanto Ribeiro verifica que a relação entre os fenômenos históricos, as formações socioculturais e as revoluções tecnológicas permitem uma compreensão mais aprofundada da evolução sociocultural humana, a partir dos processos de atualização histórica e homogeneização, Lévy ressalta o aspecto tecnológico como um elemento que atua ativamente na ordem sócio-cultural, fruto de um contexto histórico pós-moderno.

Diante disso, parte-se da hipótese de que essa relação entre os fenômenos históricos, as formações socioculturais e as revoluções tecnológicas, expostas de forma genérica pelos autores, podem ser aplicadas no âmbito da Biblioteconomia, a Documentação e a Ciência da Informação. Como esses domínios podem ser percebidos dentro de um contexto histórico-social, influenciado no tempo-espaço pelas transformações culturais, tecnológicas e sociais, pode-se constatar que a inter-relação desses fatores nos permite visualizar um panorama dessas áreas.

Como metodologia, foi realizada revisão bibliográfica, listando os períodos históricos e suas respectivas revoluções sociais e tecnológicas, seguida de análise comparativa dos elementos. Além das duas obras citadas anteriormente, foram utilizados outros trabalhos de caráter mais específico aos domínios da Biblioteconomia, a Documentação e a Ciência da Informação, com função de apoio teórico. 


\section{Das "protobibliotecas" à Biblioteconomia (3000 a.C- século XVIII)}

A partir de 3000 a.C., a humanidade, antes organizada em povos tribais ou em hordas pastoris nômades por conta da agricultura, começou a se organizar em estados rurais artesanais. A domesticação e a estruturação de um sistema produtivo alteraram a condição humana, dando-Ihe uma postura ativa na organização da produção. Por volta de 2.000 a.C., acumularam-se as inovações tecnológicas (canais, estradas, polia, balança), o que ampliou a eficácia produtiva e acabou por influenciar as relações entre os homens, configurando uma nova formação sociocultural (RIBEIRO, 2000).

A revolução urbana, além de ter sido sinônimo de aumento de produtividade e acumulação de riquezas nas mãos de grupos minoritários, propiciou a divisão social do trabalho, acarretando a estratificação social e a organização política, por meio do recrutamento de antigos líderes de guerra e religiosos que ocuparam postos de liderança em uma sucessão hereditária (ORTEGA, 2004). Tais elementos corroboraram a formação sociocultural dos Impérios teocráticos de regadio, constituindo, assim, os primeiros estados burocráticos da Antiguidade (Egito, Babilônia, Suméria e Mesopotâmia), que além dos enormes sistemas de irrigação, desenvolveram a Matemática, Astronomia, Arquitetura e as primeiras manifestações escritas (cuneiforme com os sumérios, hieroglífica com os egípcios e tábuas de argila com os mesopotâmios).

Nesse contexto burocrático estatal, foi premente a necessidade de regular a vida civil da população e conservar o conhecimento e a cultura dessas civilizações regionais, que já tinham uma preocupação com uma educação formal do saber técnico e científico. Nesse momento, constituíram-se as primeiras protobibliotecas e protoarquivos: os rudimentares catálogos primitivos em tábuas de argila, em Nippur (Suméria); em Alexandria, uma das mais famosas bibliotecas do mundo antigo, que delineou com seus filósofos, gramáticos e poetas da época o ideário dos primeiros bibliotecários; ou, ainda, as bibliotecas privadas de reis voltadas para "royal contemplation" (CASSON, 2001).

Por volta de 1.000 a.C., a expansão dos impérios teocráticos de regadio sofreu uma limitação essencial: a inviabilidade de se generalizar a irrigação sobre as áreas conquistadas por conta das diferenças ecológicas regionais. Além disso, outro fator relevante para a próxima revolução tecnológica foi o aprimoramento da metalurgia, o que transformou a fabricação de ferramentas, embarcações, transportes, a moeda cunhada e as máquinas hidráulicas. Socialmente, a formação dos impérios mercantis escravistas (Grécia, Roma e Assíria), diferentemente dos anteriores, organizados em torno de um modelo coletivo, institucionalizou a propriedade privada, incentivando o comércio e o aprisionamento de cativos de guerra (escravidão como fomento para o colonialismo mercantil). 
Outro fator marcante do período foi a criação do alfabeto fonético, que facilitou a alfabetização, permitindo juntamente com o desenvolvimento da escrita decimal - Filosofias e Ciências aplicadas, a ampliação da gama de conhecimentos, antes restrita ao sacerdócio ou realeza. Dessa forma, com uma produção documental cada vez maior, tanto de caráter burocrático (regulação da vida dos cidadãos), como testemunhal e histórico (conservação do conhecimento e da cultura), surgiram as primeiras bibliotecas em sentido estrito. Mesmo com a ausência de um corpo profissional e a indistinção entre biblioteca e arquivo, desenvolveram-se os serviços voltados à ordenação, à criação de catálogos e aos inventários (LOPÉZ-COZAR, 2002).

Até aqui, podemos observar que tanto as formações dos impérios teocráticos de regadio como os mercantis escravistas se difundiram, elevando o nível estrutural de suas civilizações a partir da atualização histórica e tendo em mãos o objeto de dominação alheia. A principal consequência desse estado de coisas foram os sucessivos ataques externos que destruíram impérios. Todavia, o contato contínuo com os povos agressores favoreceu um processo de assimilação cultural. Os impérios despóticos salvacionistas (árabes, otomanos, visigodos) contribuíram para delinear uma nova revolução tecnológica: a Pastoril (1000 d.C. a 1440), alicerçada no sistema de tração animal, na aplicação da tecnologia do ferro, à cavalaria de guerra, feudalização de áreas e principalmente 0 expansionismo salvacionista de cunho monoteísta (islamismo e cristianismo), responsável pela fusão do sistema político e religioso.

A fusão entre religião e política resultou em um controle documental. A igreja católica, por exemplo, detinha o conhecimento da época, guardando os materiais da antiguidade clássica fora do alcance do povo, em sua maioria analfabeto, e restringindo até para os monges, também muitas vezes analfabetos, à técnica da cópia de livros. Desse modo, tanto a produção bibliográfica como a ordenação, armazenamento e guarda de livros era feita pelos religiosos, que podem ser considerados os primeiros bibliotecários.

A partir do século $X V$, tanto a Europa como a região atualmente ocupada pela Rússia, depois de séculos de regressão feudal, reorganizaram-se para a reconquista de territórios, na denominada "expansão salvacionista". O amadurecimento de novas tecnologias de navegação oceânica, processos de fundição do ferro e renovação das artes de guerra propiciaram uma ruptura com o feudalismo, o que permitiu a organização da formação sociocultural dos impérios mercantis salvacionistas. Tais impérios, com o objetivo de reestruturar a Europa feudalizada, reorganizaram os centros urbanos, estruturaram Estados Nacionais em uma conjunção de poder aristocrático-clerical, desenvolvendo manufaturas e serviços comerciais e, ainda, restabelecendo o sistema mercantil, com o diferencial de estendê-lo externamente a partir da instituição do capitalismo mercantil. 
Quanto ao conhecimento da época, em 1440 temos um marco tecnológico, a invenção da prensa tipográfica por Gutenberg (a partir da prensa clássica não reutilizável criada pelos chineses), que revolucionou a produção bibliográfica possibilitando a difusão do conhecimento. Outro fator que impulsionou tal fenômeno foi a mudança de orientação do pensamento ocidental, fruto das ideias do Renascimento cultural e científico, que permitiram a modificação de valores e a crescente necessidade do homem moderno de buscar conhecimento.

Nesse contexto, as bibliotecas se converteram em "templos do saber acumulado", sendo sinônimos de orgulho nacional para os novos estados e indício de poder socioeconômico para a nova classe, a burguesia. Arquivos e bibliotecas apresentavam maior diferenciação, já que enquanto os primeiros cuidavam do complexo conjunto de documentos produzidos pelos novos estados e as sociedades emergentes (função de armazenamento e prova), as bibliotecas, com o impulso da invenção tipográfica, conseguiram fortalecer seus laços institucionais, estabelecer rotinas e ganhar maior projeção social.

O livro impresso foi o primeiro produto intelectual uniformemente reproduzido que permitiu o aumento em larga escala da difusão do conhecimento para as massas, adquirindo assim uma vigência social jamais vista. Porém, o aumento da produção bibliográfica gerou a necessidade de novas ferramentas de organização e recuperação das coleções, que cresciam vertiginosamente. Além dos catálogos e inventários que se especializaram nessa época, destacou-se o desenvolvimento das bibliografias a partir do século XVI - a origem remonta à Idade Antiga, quando eram feitas de forma limitada, mas pouco diferente da atual. Para alguns autores, esse é o embrião da Documentação.

No século XVII, a expansão marítima iniciada pelos ibéricos havia se tornado uma empresa coletiva que multiplicava colônias escravistas, mercantis e de povoamento, fazendo com que os patrimônios culturais mais divergentes fossem afetados e remodelados, acarretando uma reordenação unificadora do patrimônio cultural humano. Um exemplo disso foi o amplo movimento de secularização, incentivando a alfabetização das massas em línguas vernáculas para a leitura da bíblia, o que, posteriormente, fomentou as bases para um maior estímulo à indagação e à pesquisa. A biblioteca pública se difundia cada vez mais, e o seu acervo, além do grande número de coleções de livros, passou a ver o aumento gradativo de periódicos, reflexo do desenvolvimento científico em curso.

Outro fato importante foi a obra de Gabriel Naudé (1600-1653), Advis pour dresser um bibliothéque (1627), o primeiro manual para bibliotecários, que formalizou as bases conceituais da Biblioteconomia, fornecendo importantes conceitos, como a ideia de ordem bibliográfica. Além disso, por trazer em seu bojo o espírito do progresso e liberdade de expressão e cultura, serviu de inspiração a Montaigne e Pierre Charron durante a Revolução Francesa. Tais valores revolucionários estimularam a 
consolidação do conceito lançado por Naudé: as bibliotecas como espaços públicos e universais (CACALY, 1997).

A biblioteca pública se consolidou principalmente após a Revolução Francesa (1789-1799), que lançou as bases para os objetivos essenciais dessa instituição: satisfazer as necessidades da sociedade nos âmbitos da educação e cultura. Nesse contexto, nasceu a Biblioteconomia, disciplina encarregada de organizar, administrar e cuidar da gestão de livros, bem como a figura do profissional bibliotecário; ao lado do arquivista, tornaram-se fundamentais para a consolidação institucional de arquivos e bibliotecas. Tais profissionais, também influenciados pelo momento histórico de desenvolvimento tecnológico e científico do século XVIII, concentraram sua formação em dois aspectos: um técnico (catalogação, classificação, paleografia) e outro voltado à aquisição de cultura geral (história, literatura, ciências).

Esse espírito técnico esteve intimamente ligado à revolução tecnológica industrial, que se instaurou no mundo a partir das formações capitalistas, pela acumulação de inventos mecânicos e multiplicação da produtividade do trabalho humano, tendo seu ápice na Revolução Industrial. As formações socioculturais também refletiam tais mudanças, fortalecendo e dando um novo viés à burguesia, que se tornava industrial, criando uma nova força de trabalho, os assalariados. Diferentemente dos escravos, favoreciam, concomitantemente, a elevação do nível de produtividade e o consumo.

Se por um lado a Revolução Industrial permitiu o desenvolvimento técnico e científico influenciado pelo Iluminismo, bem como a melhora nas condições de vida da população, em relação à saúde pública, escolarização e até expectativa de vida, por outro lado, fez com que as nações neocolonizadas fossem exploradas pelas grandes potências, condenadas ao atraso e à penúria. Tal marginalização refletiu-se também no atraso quanto à produção cultural, bem como na organização da informação, em nível institucional e profissional. Na Europa, por exemplo, no final do século XVIII, nasciam as primeiras associações profissionais de bibliotecários e arquivistas, enquanto na América Latina isso só ocorreu no século XX.

\section{0 despertar da Documentação (século XIX e XX)}

No final do século XIX, com o aumento da produção bibliográfica, da pesquisa científica e o surgimento de novos suportes houve a necessidade do desenvolvimento de outras técnicas para organização e administração da informação, já que a Bibliografia não dava mais conta de tais necessidades. Enquanto as bibliotecas públicas projetavam suas atenções à educação da massa trabalhadora, produzida pela Revolução Industrial, e os arquivos procuravam se institucionalizar e resolver seus problemas de organização informacional, a Documentação abriu espaço no século XX.

Desenvolvidas simultaneamente às atividades da biblioteca pública, as práticas documentais conseguiram se delinear a partir dos trabalhos de 
Paul Otlet e La Fontaine, que sistematizaram conceitos para Documentação a partir de estudos bibliográficos. Diferente da Biblioteconomia, muito voltada ao acesso e à função educacional, a Documentação tinha o papel de "acompanhar o documento desde o instante em que ele surgiu da pena do autor até o momento em que impressionava o cérebro do leitor" (OTLET, 1997, p. 115).

Outra relevante contribuição dos autores foi a concepção de documento, que deixava de estar restrito ao suporte ou formato e passava a ser visto como um registro de um conhecimento.Tal ideia, mais tarde, foi desenvolvida pela discípula de Otlet, Suzane Briet, ao considerar documento como um evidência, ou seja, qualquer objeto poderia ser um documento desde que fosse tratado como tal, considerando para isso critérios como: materialidade, intencionalidade e organização em um sistema.

Em um contexto de ciclos de progresso das civilizações mundiais, que para cada nova tecnologia abria-se espaço para novos conflitos internos e externos, a obra de Otlet se encaixava nesse viés, pois tinha como um de seus mais ambiciosos intentos o armazenamento das representações de todo o conhecimento humano em um único local, projeto que fomentaria a paz mundial. Além disso, em $O$ Tratado de Documentação (1934), Otlet, de forma visionária, antecipou o surgimento de novas tecnologias, em especial os sistemas de hipertexto e hipermídia, frutos da revolução tecnológica desencadeada depois da II Guerra Mundial.

Os estudos da Documentação ganharam maior espaço em seu berço europeu, em especial na França, onde auferiu normalização e efetiva organização no período entre 1895 e 1937, quando para muitos chegou ao seu auge no Congresso Mundial de Documentação Universal em Paris. Tal evento sedimentou importantes discussões: normalizações catalográficas e bibliográficas, padronização de sistemas de classificação, elaboração terminológica da área, adoção de novos suportes e outros tipos de informação, além de toda produção intelectual do evento (ORTEGA, 2004).

A Documentação ganhou maior ênfase na Europa e a Biblioteconomia desenvolveu-se nos EUA a partir do fenômeno das bibliotecas públicas, de fins do século XIX à primeira metade do século XX. Nesse contexto, a biblioteca era vista como uma instituição social organizada e definida, parâmetros delineados pela Escola de Chicago, que durante os anos 20 e 30 constituíram o modelo de biblioteca nos EUA. Com bases ideológicas do campo da Sociologia e da Educação, além de aproveitar a estruturação, expansão dos serviços técnicos e das novas tecnologias (projeção em fotocopiadora e microfilmagem) das bibliotecas públicas pelo país, a Escola de Chicago teve como principal foco para seu modelo de biblioteca o acesso dos diferentes materiais pelo público. Portanto, à biblioteca cabia a responsabilidade de facilitar ao indivíduo o acesso ao conhecimento social acumulado, funcionando como uma 
organização social voltada à memória sociocultural (OLIVEIRA; ARAÚJO, 2002).

Enquanto a Biblioteconomia desenvolvia-se nos EUA a partir de um paradigma institucional, a Documentação chegava ao seu apogeu na Europa. Contudo, a potencialidade da Documentação e os propósitos documentalistas da visão pacifista de seu mentor se esvaíram com a eclosão da II Guerra Mundial, prevalecendo as preocupações com as questões políticas, econômicas e bélicas. A Revolução Termonuclear se instaurou: meios de comunicação e armas de destruição em massa proliferaram. Assim, as formações sociais posteriores refletiriam as idiossincrasias desse momento histórico.

\section{As arestas do pós-guerra e a Ciência da Informação (segunda metade do século $X X$ )}

Segundo Ribeiro (2000), a designação Revolução Termonuclear é fruto das inovações tecnológicas e das formações socioculturais (socialismo revolucionário, capitalismo industrial e nacionalismo) da segunda metade do século $X X$, que teve como fator crucial a questão energética, principalmente propiciada pela competição atômica bipolar entre EUA e URSS. Tal competição, se por um lado colocou nas mãos humanas um incomensurável poder destrutivo, por outro, ao gerar o temor do extermínio em massa, também foi sinônimo de um poder construtivo, trazendo um acelerado processo de evolução tecnológica.

A ciência, por exemplo, antes muito ligada ao plano ideológico, se transladou para um papel mais ativo e adaptável às necessidades humanas, principalmente motivada por três fatores: desenvolvimento exponencial de experimentos e conhecimentos científicos; profissionalização científica e tecnológica; e aplicação de recursos e atividades de pesquisa em programas sociais. Assim, a ciência, a tecnologia e a informação tornaram-se os motores propulsores da sociedade e base do progresso econômico.

Nesse contexto de estímulo à pesquisa científica e tecnológica, desencadeou-se uma explosão informacional, a partir da qual se criou uma demanda para a emergência de um campo preocupado com a recuperação da informação, acesso e uso dessas novas tecnologias, já que a informação ganhou um valor estratégico para os governos. Nascia assim, por volta da década de 60, nos EUA, a Ciência da Informação.

Impulsionada originalmente pelas ideias da Engenharia de Comunicação, teorias cibernéticas e sistemas de transmissão de sinais, que desenvolveram as bases para a caracterização dos modelos e processos de recuperação da informação (Information Retrieval), a Ciência da Informação também tomou como base elementos da Biblioteconomia Especializada e da Documentação. Enquanto a primeira estava muito atrelada aos aspectos sociológicos (herança da Escola de Chicago, 1930) e institucionais; a segunda foi praticamente substituída nos EUA pela Ciência da Informação, difundindo-se pela Europa. 
Fatores de diferentes naturezas podem explicar o deslocamento semântico do termo "Documentação" para "Ciência da Informação", nos EUA. No aspecto tecnológico, por exemplo, a criação dos bancos de dados ofereceu 0 acesso às informações propriamente ditas, o que na Documentação ficava restrita às referências de documentos. Quanto à natureza social, o caráter interdisciplinar da Ciência da Informação ampliou o papel da informação na sociedade, associando-a às novas tecnologias e necessidades das diversas áreas, diferente da Documentação que era vista como uma prática de uso imediato (ORTEGA, 2008). E ainda havia a questão ideológica, já que o berço das práticas documentárias era europeu, e como os EUA ambicionavam tornar-se potência mundial, nada mais natural que criar a designação para "ciência nascida em seu seio".

Na Europa, a Documentação também incorporou as noções de automatização de serviços e técnicas, além de uma perspectiva de informação científica preocupada com o acesso e a recuperação, desenvolvendo importantes centros de documentação e profissionalização. Todavia, EUA e URSS, em competição antes de tudo ideológica, ao incorporarem as inovações tecnológicas e científicas, sentiram a necessidade de demonstrarem seu poderio, denominando através dos campos responsáveis pelo tratamento e difusão da informação sua perspectiva de mundo.

Assim, enquanto nos EUA se difundiu a expressão Ciência da Informação, na URSS criou-se o termo Informatika, conceito construído pelos autores Chernyl, Gilyarevskii e Mikhailov (1973). O objeto dessa disciplina era estudar a estrutura e as peculiaridades da informação científica, bem como as leis que regiam tal atividade, sua história, teoria, método e formas de organização. Dessa forma, o ponto chave de estudo era a informação no contexto comunicativo de um sistema social voltado à mudança de estado do conhecimento, ideia que se aproximava de uma das vertentes do estudo da Ciência da Informação, que considerava o objeto de estudo, a informação, como potencial transformador do estado anômalo do conhecimento.

Os estudiosos russos destacaram-se pelo desenvolvimento de um sólido aparato conceitual, além de tentativas de delimitação do objeto, distinção dos tipos de documentos e automatização da busca. No entanto, com o fim do regime socialista, o esgotamento do financiamento para pesquisas e o problema da ambiguidade do termo "informatika" no Ocidente acabaram por favorecer a disseminação da Ciência da Informação (RADAMÉS LINARES, 2005).

Mesmo se sobrepondo e ganhando maior escala, a Ciência da Informação trouxe em seu bojo algumas arestas, como: a questão da identidade, fruto de sua natureza interdisciplinar e o problema da delimitação do objeto de estudo, supostamente informação - termo que, assim como outros que lhe são referência, como "conhecimento" e "comunicação", ainda são considerados ambíguos e polivalentes. Além disso, como área que floresceu em meio às fragmentações e relativizações 
trazidas pelo contexto pós-moderno, é de se esperar que trouxesse mais indagações que respostas.

Dessa forma, com uma identidade nebulosa e influenciada pelas fragmentações trazidas no fim do século $X X$, ocorreu a incessante tentativa da Ciência da Informação de sedimentar seu status científico e social. As principais práticas observadas foram: a produção e difusão de revistas científicas da área, o desenvolvimento de bancos de dados, a organização de sociedades científicas de profissionais, além da preocupação com a formação de profissionais na área.

Novas tecnologias de informação, especialmente no campo da Informática, revolucionaram o conceito de informação no fim do século XX. Armazenamento, tratamento, conservação e recuperação podiam ser feitas automaticamente e as redes de informação permitiam uma difusão informacional nunca vista. O próprio modelo de informação também se transformou. Antes orientado para o profissional da informação (bibliotecário), em um trabalho individual e voltado a acervos, aos poucos foi se direcionando para o usuário e considerando a perspectiva de trabalho coletivo, tomando como base o próprio fluxo informacional (LE COADIC, 2004).

Assim, no final do século $X X$, caminhava-se para a designação de "civilização da humanidade", cunhada por Ribeiro (2000), momento em que já não era possível delimitar o homem "produzido" pela Revolução Termonuclear com rótulos étnicos ou regionais. Tanto as tecnologias da época como as promessas futuras redimensionavam as relações sociais e econômicas, já não bipolarizadas, mas, sobretudo, plurais e polivalentes. O próprio paradigma positivista racional, científico e determinista mostrava-se em crise. Instituições tradicionais, como as bibliotecas, e as novas ciências, como a Ciência da Informação, mostravam-se fragilizadas diante do porvir.

\section{Biblioteconomia, Documentação e Ciência da Informação: os descaminhos do século XXI}

Até o momento, tendo como base o subsídio teórico de Ribeiro (2000), foi possível associar as origens e o desenvolvimento da Biblioteconomia, Documentação e Ciência da Informação às noções históricas, culturais e tecnológicas. O autor deixa em aberto para as "civilizações da humanidade" os novos desafios trazidos com a Revolução Termonuclear, ansiando por mudanças sociais e culturais a longo prazo, que dessem ao homem contemporâneo "ferramentas" para melhor lidar com a coletividade humana.

Na prática, o "sonho" de Ribeiro ainda não se realizou, mas podemos dizer que de certa maneira o olhar de uma coletividade é um aspecto importante do século XXI. Diferente do modelo positivista focado no sujeito racional e em um "saber disciplinado", vivemos uma reconfiguração do saber, em que um "coletivo pensante" olha em perspectiva o mundo, extraindo não a divisão de saberes e objetos de 
estudo, mas problemas a serem desvendados e temáticas a serem desveladas.

A noção de "coletivo pensante" é trabalhada por Lévy (1998). Tal noção é denominada pelo autor como "ecologia cognitiva", por representar uma coletividade dinâmica, "homem-coisa", ou seja, um conjunto de indivíduos cheios de singularidades e subjetividades mutantes, mas que em seu "fazer e desfazer", contribuem com a nossa apreensão do real. Essa apreensão é mediada pelas "tecnologias intelectuais", que segundo o autor, são utilizadas pelas categorias usuais da Filosofia do Conhecimento e articuladas ao uso histórico na constituição das culturas e inteligência humana.

No mundo contemporâneo, sujeito e objeto se confundem; espaço e tempo são redimensionados, $e$, com isso, as relações humanas se transformam. Homem, trabalho, comunicação, conhecimento, elementos que ao se relacionarem dependem de uma "metamorfose incessante dos dispositivos informacionais" (LÉVY, p.7, 1998). Diante de tais mudanças, como ficam os domínios que lidam com esses dispositivos informacionais? Foram afetados em seu bojo pelas transformações da pós-modernidade?

As bibliotecas, juntamente com os arquivos, foram as primeiras instituições que lidaram com a informação, tendo o importante papel na preservação documental. Além disso, destacam-se os serviços, procedimentos técnicos e linguagens desenvolvidos, pensando-se no acesso e uso dos documentos, o que Ihes conferiu relevância social na construção do conhecimento. Todavia, o excesso de tradições e regras cristalizaram tanto alguns procedimentos técnicos como a postura profissional, geralmente pouco afeita às mudanças (ORTEGA, 2004). Essa atitude, arraigada à tradição biblioteconômica e também arquivística, refrata uma dificuldade atual de uma constituição científica de ambas como áreas do conhecimento.

A Biblioteconomia, em especial, mesmo com a incorporação de novos equipamentos tecnológicos à sua rotina, alterando serviços básicos como a catalogação, (utilização das redes colaborativas), ou até o atendimento ao usuário (serviço de referência virtual), ainda não se constitui como uma área científica. Segundo Pinheiro (1999), a Biblioteconomia precisaria de uma "ciência" para lhe dar respeitabilidade acadêmica, já que mesmo com a disseminação de seus equipamentos físicos no âmbito digital, não conseguiu relacioná-los efetivamente com base na produção e uso da informação em um contexto.

A Documentação, posterior à Biblioteconomia, voltou-se ao desenvolvimento de técnicas e princípios preocupados com a organização e recuperação informacional, voltada ao tratamento documental. Essas ações engendram-se independente do tipo de documental ou de suporte, permitindo enxergar o documento em seu contexto de aplicação (ORTEGA, 2008). Porém, mesmo trabalhando ativamente na otimização de processos e técnicas documentárias, servindo realmente para a Ciência da Informação, a Documentação foi praticamente excluída dos estudos anglosaxões e simplesmente substituída pela Ciência da Informação. 
Atualmente, alguns autores anglo-saxões como Rayward e Buckland, escreveram trabalhos resgatando o aporte teórico da Documentação difundida na Europa, especialmente as obras de Otlet e de seus discípulos como Briet.No entanto, uma das obras-chave para área, o Tratado de Documentação (1934), ainda não teve uma tradução para o inglês. Tais indícios revelam que mesmo que a Documentação tenha dado "insumos", tanto para a Ciência da Informação, em sua constituição científica, como para a Biblioteconomia, na adequação de processos e práticas documentais, ainda não tem seu devido reconhecimento.

A Ciência da Informação por sua vez nasceu mais próxima do contexto pós-moderno, o que lhe garantiu maior "flexibilidade" e "tolerância" relativa à sua consolidação científica. Para Wersig (1997), a Ciência da Informação é uma "ciência pós-moderna", que tem como um de seus principais atributos a interdisciplinaridade, caráter que lhe "liberta" das "amarras disciplinares" do paradigma positivista e Ihe oferece um olhar multifacetado e temático. Por outro lado, tal fragmentação em diversas vertentes do saber ou mesmo a diversidade de profissionais e pontos de vista, dificultam a construção de uma identidade.

\section{Considerações finais}

Verificar que a Biblioteconomia, a Documentação e a Ciência da Informação são áreas relacionadas conceitual e historicamente parece algo notório, visto suas origens contíguas e suas práticas intercambiáveis. Todavia, ao se observar, por entre a sucessão de fatos históricos, o desvelar das revoluções tecnológicas e das formações socioculturais, é possível notar como tais aspectos influenciaram tanto o surgimento como o desenvolvimento de tais áreas. Assim, através da perspectiva históricosocial, é possível ter não só um panorama das áreas em questão, mas uma compreensão mais aprofundada de seus fenômenos, práticas e necessidades.

Nas relações entre homens, trabalho e produção de conhecimento, por exemplo, verifica-se uma incessante metamorfose dos dispositivos informacionais no decorrer do tempo, frutos dos aspectos sociais, ideológicos e tecnológicos. Esse último, muitas vezes rotulado como uma "potência má", na verdade, também é uma dimensão de força que participa ativamente da ordem cultural, social e histórica. Dessa forma, não se deve olhar as "novas tecnologias" como instrumentos bárbaros e isolados das práticas sociais. É necessário lembrar que tanto a impressão como a escrita foram também "técnicas" polêmicas em suas épocas, e assim como as " mal compreendidas tecnologias atuais", na verdade estão impregnadas de valores culturais, sociais e históricos.

A perspectiva pós-moderna, mesmo arraigada às indagações e fragmentações, tem a vantagem de mostrar não apenas os caminhos possíveis, mas permitir traçar atalhos, criar bifurcações, saídas ou até mesmo parar e recomeçar sob outro ponto de vista. Nesse contexto pluridiverso e relativo pode-se mais facilmente enxergar que aspectos 
como história, sociedade e tecnologia estão articulados e coexistem. A Biblioteconomia, Documentação e a Ciência da Informação como domínios imersos nesse contexto, refletem e refratam essas inter-relações em seus dispositivos informacionais. As nuances com que cada domínio enxerga a informação, desvela tanto sua maneira de lidar com a perspectiva dialógica dos aspectos históricos, sociais e tecnológicos, como indica suas "escolhas" na tentativa de consolidação como área científica.

\section{Referências}

CACALY, S. (Dir.). Dictionnaire encyclopédique de l'information et de la documentation. Paris: Nathan, 1997.

CASSON, L. Libraries in the ancient world. London: Yale University Press: New Haven, 2001.

LE COADIC, Y. A ciência da informação. 2. ed. Brasília: Briquet de Lemos, 2004.

LÉVY, P. As tecnologias da inteligência: o futuro do pensamento na Era da Informática. Rio de Janeiro: Editora 34, 1998.

LÓPEZ-CÓZAR, E. D. La investigacíon em biblioteconomia y documentación. Asturias: Ediciones Trea, 2002. (Biblioteconomía y administración cultural, 61).

OLIVEIRA, M.; ARAÚJO, E. A. Os paradigmas da biblioteconomia e da ciência da informação e os novos contextos de informação. In: CASTRO, C. A. (Org.). Ciência da informação e biblioteconomia: múltiplos discursos. São Luis: EDUFMA, 2002.

ORTEGA, C. D. Relações históricas entre Biblioteconomia, Documentação e Ciência da Informação. DataGramaZero - Revista de Ciência da Informação, v.5, n.5, out., 2004. Disponível em: <http://www.dgz.org.br/out04/Art 03.htm>. Acesso em: 10 mar. 10.

- Surgimento e consolidação da Documentação: subsídios para compreensão da história da Ciência da Informação no Brasil. Perspectivas em Ciência da Informação, v. 14, número especial, p. 59-79, 2008. Disponível em: $<$ http://www.eci.ufmg.br/pcionline/index.php/pci/article/viewFile/899/626 $>$. Acesso em: 20 mar.10.

OTLET, P. Tratado de documentación: el libro sobre el libro-teoria y práctica. España: Universidad Murcia, 1997.

PINHEIRO, L. V. R. Campo interdisciplinar da Ciência da Informação: fronteiras remotas e recentes. In: __. Ciência da Informação, ciências sociais e interdisciplinaridade. Brasília: IBICT, 1999.

RADAMÉS LINARES, C. Ciencia de la Información: su historia y epistemología. Bogotá, Colombia: Editorial Rojas Eberhard, 2005. 
RIBEIRO, D. O processo civilizatório: etapas da evolução sociocultural. São Paulo: Companhia das Letras; Publifolha, 2000. (Grandes nomes do pensamento brasileiro).

WERSIG, G. Information Science: the study of postmodern knowledge usage. Information Processing \& Management, v. 29, n. 2, p. 229-239, 1991. 